\title{
Musculoskeletal practices for the preparticipation physical examination
}

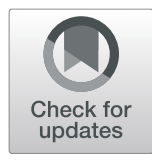

Connor Corrente ${ }^{1 *}$ (D), Matthew Silvis ${ }^{2}$, Joseph Murphy ${ }^{3}$, Robert Gallo ${ }^{4}$ and Cayce Onks ${ }^{2}$

\begin{abstract}
Background: Little is known about the musculoskeletal (MSK) exam providers use during the Preparticipation Physical Examination (PPE). The primary aims of this study were to determine current practice with regards to the MSK screening exam, if goals are being met, and if there may be opportunities for improvement.

Methods: This cross-sectional survey-based study utilized a REDCap instrument that was distributed to members of the American Academy of Family Physicians (AAFP) and the American Medical Society for Sports Medicine (AMSSM). Questions focused on participant demographics and MSK exam practices for the PPE. Descriptive statistics were used.

Results: The study had a total of 616 participants with a response rate of $9 \%$. The majority of respondents (82\%) were familiar with the 4th Edition PPE Monograph and $80 \%$ either moderately or strongly agreed that they use this as a guideline for their MSK screening exam. The 90 s MSK screening test was implemented by $52 \%$ of the participants. The majority of participants use an orthopedic exam as part of their PPE (82\%). Ninety-two percent of participants felt satisfied that their MSK exam would screen for current injury, while only $42 \%$ were satisfied that it effectively screened for future injury. $86 \%$ of participants agree that the MSK exam should be performed, while $26 \%$ said that they don't perform a physical exam at all.
\end{abstract}

Discussion: There is a lack of understanding of the PPE Monograph as there is wide variability in MSK screening techniques providers use despite the majority of participants being familiar with the guidelines described in the monograph. Additionally, providers don't believe that the MSK exam screens for future injury.

Conclusions: The goals of the MSK portion of the 4th Edition PPE monograph are not adequately being met and there is a need for further research to validate screening exams for the prevention of MSK injury.

Keywords: Musculoskeletal (MSK), Preparticipation Physical Examination (PPE), Injury prevention, MSK screening exam

\section{Background}

Athletes aged 5-14 suffered an estimated 5.6 million recreation related injuries requiring medical attention from 2011 to 2014 [1] The High School Sports-Related Injury Surveillance Study showed that ankle and knee injuries were two of the most common high school sportsrelated injuries, accounting for over $30 \%$ of all high school sports-related injuries in the 2018-19 school year

\footnotetext{
* Correspondence: correnteconnor@gmail.com

${ }^{1}$ Penn State College of Medicine, 700 HMC Crescent Road, Hershey, PA 17033, USA

Full list of author information is available at the end of the article
}

[2]. Longer-term consequences of sports injuries include predisposition to recurring injuries, earlier sports termination/dropout, and potentially compromised physical and psychological health [3].

The current standard of care for screening athletes at risk for injury and illness is the Preparticipation Physical Examination (PPE), but there has been no conclusive evidence that supports the effectiveness of the musculoskeletal (MSK) PPE to accurately identify or prevent at risk populations from injury $[4,5]$. Despite not having a validated screening exam, the musculoskeletal portion of the PPE has been found to be the most common cause

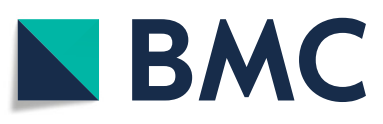

(c) The Author(s). 2021 Open Access This article is licensed under a Creative Commons Attribution 4.0 International License, which permits use, sharing, adaptation, distribution and reproduction in any medium or format, as long as you give appropriate credit to the original author(s) and the source, provide a link to the Creative Commons licence, and indicate if changes were made. The images or other third party material in this article are included in the article's Creative Commons licence, unless indicated otherwise in a credit line to the material. If material is not included in the article's Creative Commons licence and your intended use is not permitted by statutory regulation or exceeds the permitted use, you will need to obtain permission directly from the copyright holder. To view a copy of this licence, visit http://creativecommons.org/licenses/by/4.0/. The Creative Commons Public Domain Dedication waiver (http://creativecommons.org/publicdomain/zero/1.0/) applies to the data made available in this article, unless otherwise stated in a credit line to the data. 
of disqualification for athletes, mostly through the history and review of systems form [6].

The primary goal of the PPE as described in the 4th Edition PPE Monograph, which is now an older version but was used at the time of this study, is to (1) screen for conditions that may be life-threatening or disabling, and (2) screen for conditions that may predispose individuals to injury or illness [5]. Currently, there is no standardization for healthcare providers on how the PPE is completed, and there are questions surrounding the effectiveness of the PPE in meeting its objectives to properly screen athletes. In a study completed in 2014, it was found that healthcare providers overall were unaware of the PPE screening guidelines, and that knowledge of the Fourth Edition PPE Monograph led to increased satisfaction with the PPE as a screening tool [7].

Effective screening tests must satisfy 2 requirements as described by the US Preventive Services Task Force: (1) the test must be able to detect abnormalities earlier than without screening and (2) the screening must be accurate [8]. Due to the need to understand more completely how to better screen athletes for MSK injury we designed a survey to gain information from physicians performing PPE's. Our aims were to understand current physician practices in regard to the MSK screening exam, if physicians who perform PPEs feel the current goals of the PPE are being met, and if there may be opportunities for education in teaching of the MSK screening examination.

\section{Methods}

Following institutional review board approval, members from the American Academy of Family Physicians (AAFP) and the American Medical Society for Sports Medicine (AMSSM) were recruited for the study. Inclusion criteria included current practicing physicians in primary care, primary care sports medicine, and sports orthopedics that perform the PPE as part of his/her practice. Exclusion criteria included providers who are not currently practicing, and individuals that do not perform the PPE as part of their practice.

The study utilized a cross-sectional survey-based REDCap instrument for data collection. 3,000 members of the AAFP were mailed postcards that contained a link and scannable QR code for participants to access the survey and 3,871 members of the AMSSM were sent an email that was generated through the organization on two occasions, one month apart, containing a link to the survey.

The survey contained a total of 24 questions and was separated into two main sections: a series of questions regarding the demographics of each participant followed by questions pertaining to participants' MSK screening practices for the PPE. Demographic questions investigated the number of years of clinical practice, specialty of provider, location of practice, and level of athlete (middle school through professional) typically seen. The MSK screening questions involved a variety of Likert scale, multiple select, and yes/no questions exploring providers' satisfaction that their screen is appropriate for current or future injury, knowledge of the 4th Edition PPE Monograph, what physical exam tests are commonly performed in the PPE, thoughts on the value of the MSK screening exam, and if the PPE is adjusted based on athlete level. Additionally, information regarding the number of PPEs performed per year, most common age group of athletes screened, and facilities in which the PPEs are being performed in was collected. Prior to administration, the survey was reviewed for clarity by 3 board certified sports medicine physicians (two primary care and one orthopedic), 2 family practice physicians, and 1 certified athletic trainer who were not involved in the creation of the questionnaire. Descriptive statistics were used in the analysis of the data, comparing frequency and percentages of responses for each answer choice.

\section{Results}

A total of 616 out of 6871 participants (9\%) responded to the survey. The majority of participants, $72 \%$, were family medicine physicians with the remaining $28 \%$ being composed of orthopedic, internal medicine, emergency medicine, pediatric, and physical medicine and rehabilitation physicians. Participants practiced across 46 states collectively.

Variability in the MSK screening exam is depicted in Fig. 1 . The $90 \mathrm{~s}$ MSK screening test was implemented by $52 \%$ of the participants, the most common among physicians. The majority of participants who perform a MSK exam use an orthopedic exam as part of their PPE (82\%). Twenty-six percent of participants reported that they do not perform a physical exam at all as part of their MSK screening examination, while $86 \%$ of participants agreed that the MSK exam should be performed. Ninety-two percent of participants felt satisfied that their MSK examination screened for current injury, while only $42 \%$ were satisfied that it effectively screened for future injury. One of the main barriers to performing portions of the MSK screen was time ( $46 \%$ ), while $22 \%$ reported lack of evidence for the exam as their reason.

Educationally, $51 \%$ received training for the MSK PPE in residency, and $62 \%$ had training in fellowship. The majority of respondents $(82 \%)$ were familiar with the 4th Edition PPE Monograph and $80 \%$ either moderately or strongly agreed that they use this as a guideline for their MSK screening exam. Data comparing knowledge of the monograph and number of PPEs completed yearly showed that of the participants that complete more than 100 PPEs yearly, there is a higher percent of participants 


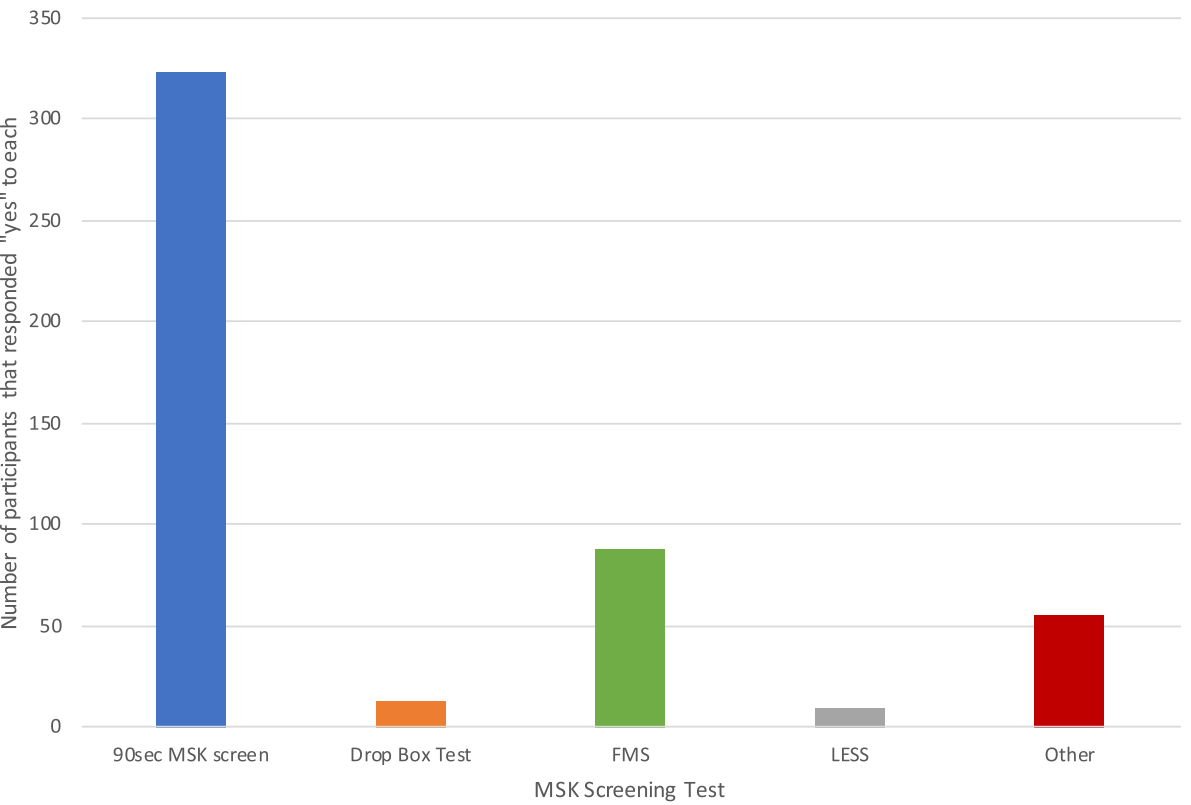

Fig. 1 Variability in MSK screening tests used during the PPE $(n=616)$. The 90 second MSK screening exam was the most common among all participants. (FMS = Functional Movement Screen; LESS = Landing Error Scoring System; Other = mixed responses including Duck Walk, individual joint examinations, and focused examination of areas based on history)

(88\%) with knowledge of the 4th Edition PPE Monograph compared to those who do not have knowledge of the PPE monograph (12\%). Additionally, of those that were aware of the 4th Edition PPE Monograph, most participants $(59 \%)$ completed more than 75 PPEs per year, while those that completed 25 or less PPEs per year only made up $11 \% .13 \%$ reported no knowledge of the $90 \mathrm{~s}$ MSK screening test that is included in the 4th Edition PPE Monograph. These results are summarized in Table 1.

\section{Discussion}

There are a variety of approaches that are used for the MSK screening examination during the PPE. Most participants believe that the MSK exam should be performed and that it effectively screens for current injuries, but the majority of providers do not believe that the MSK exam adequately screens for future injury. This data confirmed our perception that providers do not believe in the predictive ability of the screen. To that end almost a third of respondents reported that they do not perform a physical exam at all. This perception is also in agreement with literature investigating the effectiveness of the MSK PPE, which shows there has been no convincing evidence that the MSK PPE is effective at accurately identifying or preventing at risk athletes from injury $[4,9,10]$.

Most participants were aware of the 4th Edition PPE Monograph and reported that they primarily use it as their guideline. Even with participants reporting using the monograph as their guideline for the MSK screen, there is still a lot of variability in how the screen is being performed, with half of the participants using the $90 \mathrm{~s}$ MSK screening test, $14 \%$ using the Functional Movement Screen (FMS), and close to a third not using a physical exam at all for the screen. Approximately $46 \%$ of participants reported lack of time as a barrier to performing some portions of the MSK PPE, providing some explanation as to why this variability may exist. Another explanation for the inconsistency could be due to educational differences amongst providers as there was variability in where providers were taught the MSK exam. Fifty-one percent of respondents received training for the MSK PPE in residency and $62 \%$ in fellowship programs, which highlights the lack of standardization in curriculums. As curriculums are updated there should be discussions regarding the value of the MSK screening and if standardization can improve the quality of MSK screenings provided.

Our findings support a lack of understanding of the PPE monograph given the wide variability in MSK screening exam techniques used while being aware of the PPE guidelines. This calls attention to the need for continued standardization of the MSK screening exam, as well as further research to validate objective screening exams for the prevention of MSK injury. Screening exams should be explored to look at the relationships between screening tests and risk factors in relevant populations to determine what tests are appropriate and effective in identifying high-risk populations [9]. A recent study by Teyhen et al. was able to show in a military population that the sum of a number of risk factors was able to produce a highly sensitive model for identifying 
Table 1 Participant Demographics and PPE Experience Data

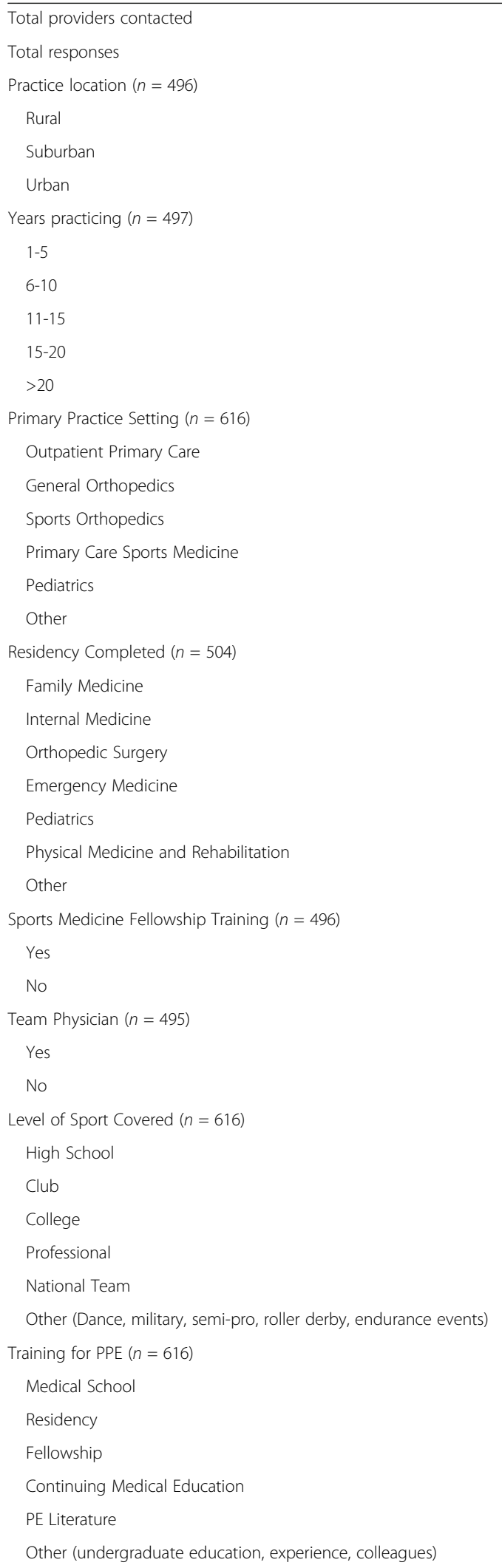

6871

$616^{\mathrm{a}}$

$56(11.29 \%)$

$263(53.02 \%)$

177 (35.69\%)

$184(37.02 \%)$

$96(19.32 \%)$

$65(13.08 \%)$

$54(10.87 \%)$

$98(19.72 \%)$

147 (23.86\%)

17 (2.76\%)

78 (12.66\%)

314 (50.97\%)

8 (1.30\%)

36 (5.84\%)

$360(71.43 \%)$

30 (5.95\%)

1 (0.20\%)

18 (3.57\%)

47 (9.33\%)

35 (6.94\%)

$13(2.58 \%)$

439 (88.51\%)

57 (11.49\%)

393 (79.39\%)

102 (20.61\%)

283 (45.94\%)

$75(12.18 \%)$

273 (44.32\%)

122 (19.81\%)

$51(8.28 \%)$

$12(1.95 \%)$

139 (22.56\%)

314 (50.97\%)

$380(61.69 \%)$

$123(19.97 \%)$

174 (28.25\%)

$9(1.46 \%)$
Table 1 Participant Demographics and PPE Experience Data (Continued)

Familiarization of $4^{\text {th }}$ Edition PPE Monograph $(n=466)$

Yes

$383(82.19 \%)$

No

$83(17.81 \%)$

Use of PPE Monograph as guideline $(n=382)$

Disagree Strongly

$4(1.05 \%)$

Disagree Moderately

$8(2.09 \%)$

Disagree Slightly

$13(3.40 \%)$

Agree Slightly

$50(13.09 \%)$

Agree Moderately

$180(47.12 \%)$

Agree Strongly

$127(33.25 \%)$

Satisfied with MSK screening exam for CURRENT injury $(n=466)$

Yes

$431(92.49 \%)$

No

$35(7.51 \%)$

Satisfied with MSK screening exam for FUTURE injury $(n=466)$

Yes

$194(41.63 \%)$

No

$272(58.37 \%)$

Location where PPE is performed most commonly $(n=616)$

Normal office patient encounter

$370(60.06 \%)$

On-field with team

$16(2.60 \%)$

Gymnasium

$201(32.63 \%)$

Physical Therapy Clinic

$18(2.92 \%)$

Athletic Training Room

$264(42.86 \%)$

Other

$43(6.98 \%)$

Age groups most commonly assessed (years) $(n=466)$

$<12$

$5(1.07 \%)$

13-18

$258(55.36 \%)$

$18-25$

$198(42.49 \%)$

$>25$

$5(1.07 \%)$

Number of PPE performed yearly $(n=466)$

$0-25$

$63(13.52 \%)$

26-50

77 (16.52\%)

$51-75$

$68(14.59 \%)$

76-100

$54(11.59 \%)$

$>100$

$204(43.78 \%)$

Details the demographic data of respondents in the study as well as prior experiences and opinions in regards to the PPE

${ }^{a}$ Total responses may not equal total number of participants due to missing data

those at risk for MSK injury [11]. This highlights that future MSK screenings should not focus on a single screen, but that a multivariate model with multiple risk factors could successfully identify a high-risk population. Injury prevention programs have shown to be effective in reducing injuries in athletes across a range of sports [12-14]. Identifying the high-risk population would provide an opportunity to direct limited prevention resources to the most at-risk individuals with the ultimate goal to reduce overall injury risk. 
There are several limitations to our study. Our survey was the first that we are aware of that looked to gain provider insight to the MSK exam. As with any questionnaire-based research study, limitations regarding validation of the instrument used is of paramount concern. Validation of a questionnaire requires a process to determine construct, criterion, and content validity, amongst others. We addressed content validity through independent review of the questionnaire by 3 sports medicine physicians (two primary care and one orthopedic), 2 family medicine physicians, and 1 certified athletic trainer not involved in the creation of the questionnaire. Because there are no other instruments available to assess similar information, we were unable to assess criterion validity. Given the simple design of the questionnaire, we did not believe that it was necessary to assess construct validity [15]. The study was also limited due to a low response rate of $9 \%$, however, other web-based survey studies targeting members of the AMSSM had similar response rates [16-18]. Additionally, it is important to note that the response rate is slighter higher than $9 \%$ due to crossover of providers being active members of both the AAFP and AMSSM. The low response rate from providers specializing in fields other than family medicine did not allow for further analysis across specialties.

\section{Conclusions}

This study provides evidence for variability in MSK screening practices. It also highlights physician concerns that the goals of the PPE are not being met with the MSK screening. Finally, there may be a need to improve educational efforts in residencies and fellowships. Future steps include creation of a validated MSK screening model, similar to other primary prevention screening models (CAD, Colon cancer, etc.), that accomplishes the goals of the MSK portion of the PPE, which can then be implemented to be a standard part of the PPE exam.

\section{Abbreviations \\ MSK: Musculoskeletal; PPE: Preparticipation Physical Examination; AAFP: American Academy of Family Physicians; AMSSM: American Medical Society for Sports Medicine; FMS: Functional Movement Screen}

\section{Acknowledgements}

Thank you to Alan Adelman, Amanda Taylor Gehman, and Jessica Wright for your support in the development of the study protocol, administrative support, and financial support of this study. Thank you also to our statistician Erik Lehman for providing support in the data analysis of this study. The abstract to this manuscript was accepted and presented as a poster presentation at the 2020 American Medical Society for Sports Medicine Annual Conference.

\section{Authors' contributions}

CC was involved in the development of the IRB and data collection instrument, data analysis and interpretation, and manuscript preparation. CO oversaw all aspects of the study, including study design, data analysis and interpretation, and manuscript preparation. MS, JM, and RG each contributed to study design and manuscript preparation. All authors read and approved the final manuscript.

\section{Authors' information}

MS is a board-certified Primary Care Sports Medicine physician, serves as the Division Chief of Primary Care Sports Medicine at Penn State Milton S. Hershey Medical Center, and is the team physician for the Hershey Bears Hockey Club and Hershey High School. JM serves as Director and Assistant Professor of Athletic Training at Lebanon Valley College. RG is a board-certified Orthopedic Sports Medicine physician and serves as the medical director for the Harrisburg Senators baseball team. CO is a Certified Athletic Trainer and board-certified Primary Care Sports Medicine Physician, and serves as the team physician for Lebanon Valley College.

\section{Funding}

Funding was provided by the Department of Family and Community Medicine at Penn State Milton S. Hershey Medical Center to support distribution of postcards to members of the AAFP for participant recruitment. There was no further involvement of the funding body outside of recruitment.

\section{Availability of data and materials}

The datasets generated and/or analyzed during the current study are available in the REDCap repository and available from the corresponding author on reasonable request.

\section{Declarations}

\section{Ethics approval and consent to participate}

This study was approved by the Scientific Review Committee of the Department of Family and Community Medicine as well as the Human Subjects Protection Office of the Institutional Review Board at Penn State Milton S. Hershey Medical Center which determined that the research met the criteria for exempt research. No identifiable protected health information (PHI) was accessed, used, or disclosed in this study. Participants were asked to indicate their consent via REDCap, and the survey questionnaire would not begin until consent was given. A copy of the consent was available to download for participants to have on file.

\section{Consent for publication}

Not applicable.

\section{Competing interests}

The authors declare that they have no competing interests.

\section{Author details}

${ }^{1}$ Penn State College of Medicine, 700 HMC Crescent Road, Hershey, PA 17033, USA. ${ }^{2}$ Department of Orthopedics and Rehabilitation \& Family and Community Medicine, Penn State Milton S. Hershey Medical Center, 500 University Drive, H154, Hershey, PA 17033, USA. ${ }^{3}$ Department of Athletic Training, Lebanon Valley College, 212 Arnold Pavilion, Annville, PA 17003, USA. ${ }^{4}$ Department of Orthopedics and Rehabilitation, Penn State Milton S. Hershey Medical Center, 500 University Drive, Hershey, PA 17033, USA.

Received: 9 March 2021 Accepted: 19 July 2021

Published online: 04 August 2021

\section{References}

1. Sheu Y, Chen L. and Hedegaard H. Sports-and recreation-related injury episodes in the United States 2011-2014. Natl Health Stat Rep. 2016:99: $1-10$.

2. Comstock R, Pierpoint L, Summary Report. National High School SportsRelated Injury Surveillance Study, 2018-2019 School Year. Colorado School of Public Health/University of Colorado Anschutz Medical Campus. http:// www.ucdenver.edu/academics/colleges/PublicHealth/research/Resea rchProjects/piper/projects/RIO/Documents/Original\%20Report_\%202014_15. pdf.

3. Stracciolini A, Casciano R, Levey Friedman H, Meehan WP 3rd, Micheli LJ. Pediatric sports injuries: an age comparison of children versus adolescents. Am J Sports Med. 2013;41(8):1922-9 PMID: 23739684. 
4. Andujo VD, Fletcher IE, Mcgrew C. Musculoskeletal preparticipation physical evaluation - does it lead to decreased musculoskeletal morbidity? Curr Sports Med Rep. 2020;19(2):58-69. https://doi.org/10.1249/jsr. 0000000000000683.

5. Bernhardt DT, Roberts WO. American Academy of Family Physicians; American Academy of Pediatrics; American College of Sports Medicine; American Medical Society for Sports Medicine; American Orthopaedic Society for Sports Medicine; and American Osteopathic Academy of Sports Medicine. PPE: Preparticipation Physical Evaluation, 4th Edition. Elk Grove: American Academy of Pediatrics; 2010.

6. Bakken A, Targett S, Bere T, et al. Health conditions detected in a comprehensive periodic health evaluation of 558 professional football players. Br J Sports Med. 2016;50(18):1142-50.

7. Madsen NL, Drezner JA, Salerno JC. The preparticipation physical evaluation: an analysis of clinical practice. Clin J Sport Med. 2014;24(2):142-9. https:// doi.org/10.1097/jsm.0000000000000008.

8. United States Preventive Services Task Force. Guide to clinical preventive services. Alexandria: International Medical Publishing; 1996.

9. Bahr R. Why screening tests to predict injury do not work-and probably never will... A critical review. Br J Sports Med. 2016;50(13):776-80. https:// doi.org/10.1136/bjsports-2016-096256.

10. Labotz M, Bernhardt DT. Preparticipation physical examination: Is it time to stop doing the sports physical? Br J Sports Med. 2016;51(3):151-2. https:// doi.org/10.1136/bjsports-2016-096892.

11. Teyhen DS, Shaffer SW, Goffar SL, Kiesel K, Butler RJ, Rhon DI, Plisky PJ. Identification of risk factors prospectively associated with musculoskeletal injury in a warrior athlete population. Sports Health. 2020;12(6):564-72. https://doi.org/10.1177/1941738120902991.

12. Brunner R, Friesenbichler B, Casartelli NC, Bizzini M, Maffiuletti NA, Niedermann K. Effectiveness of multicomponent lower extremity injury prevention programmes in team-sport athletes: an umbrella review. $\mathrm{Br} J$ Sports Med. 2018;53(5):282-8. https://doi.org/10.1136/bjsports-2017-098944.

13. Grimm NL, Jacobs JC, Kim J, Amendola A, Shea KG. Ankle injury prevention programs for soccer athletes are protective. J Bone Joint Surg. 2016;98(17): 1436-43. https://doi.org/10.2106/jbjs.15.00933.

14. Thorborg K, Krommes KK, Esteve E, Clausen MB, Bartels EM, Rathleff MS. Effect of specific exercise-based football injury prevention programmes on the overall injury rate in football: a systematic review and meta-analysis of the FIFA 11 and 11 + programmes. Br J Sports Med. 2017;51(7):562-71. https://doi.org/10.1136/bjsports-2016-097066.

15. Brophy $\mathrm{R}$, et al. Understanding the meniscus injury and expectations of meniscus surgery in patients for orthopaedic care. Arthroscopy. 2015;31(12): 2295-300.

16. Stache S, Howell D, Meehan WP 3rd. Concussion management practice patterns among sports medicine physicians. Clin J Sport Med. 2016;26(5): 381-5. https://doi.org/10.1097/JSM.0000000000000270 PMID: 26584436.

17. Taranto E, Fishman M, Benjamin H, Ross L. Genetic testing by sports medicine physicians in the united states: attitudes, experiences, and knowledge. Sports (Basel). 2018;6(4):145. https://doi.org/10.3390/sports604 0145 PMID: 30424536; PMCID: PMC6315998.

18. Pascale B, Steele C, Attipoe S, O'Connor FG, Deuster PA. Dietary Supplements. Clin J Sport Med. 2016;26(2):139-44. https://doi.org/10.1097/ JSM.00000000000000213.

\section{Publisher's Note}

Springer Nature remains neutral with regard to jurisdictional claims in published maps and institutional affiliations.

Ready to submit your research? Choose BMC and benefit from:
- fast, convenient online submission
- thorough peer review by experienced researchers in your field
- rapid publication on acceptance
- support for research data, including large and complex data types
- gold Open Access which fosters wider collaboration and increased citations
- maximum visibility for your research: over 100M website views per year
At BMC, research is always in progress.
Learn more biomedcentral.com/submissions

